\title{
PENGATURAN SANKSI PIDANA BAGI PELAKU PEMBAKARAN HUTAN
}

\author{
Sang Bagus Nyoman Wahyuda Putra, I Nyoman Gede Sugiartha, Luh Putu Suryani \\ Fakultas Hukum, Universitas Warmadewa, Denpasar-Bali, Indonesia \\ wahyudaputra99@gmail.com, nyomansugianha4@gmail.com, putusuryani099@gmail.com
}

\begin{abstract}
Abstrak
Pembakaran alas yang semakin masif berlangsung pada setiap tahunnya di Nusantara karena banyaknya pembukaan lahan dengan cara membakar hutan. Atas hal itu, pembakaran alas yang melebar mampu mengakibatkan kehancuran alam menyebabkan terusiknya kebugaran warga, berlokasi diam, serta memperoleh alam kehidupan yang bagus serta bugar ialah kelayakan warga semacam yang disuarakan pada pasal $28 \mathrm{~h}$ ayat (1) Undang-undang Dasar RI 1945.Tujuan penelitian ini untuk mengetahui pengaturan hukum bagi pwlaku pembakaran hutan dan mengetahui sangsi pidana bagi pelaku tindak pidana kebakaran hutan. Meode yang digunakan dalam penyusunan penelitian ini ialah pengkajian hukum normatif mempergunakan kajian permasalahan dengan menggunakan dasar hukum yang berlaku peraturan perUndang-undangan ysng terdapat pada literature. Cara yang dipakai untuk riset berikut ialah yuridis normatif, bersifat deskriptif analitis, dan memakai skema Peraturan PerUndang-undangan, Pelaksana aksi penghangusan alas serta tanah yang terusrnenerus melaksanakan penghangusan alas seharusnya peyangga hukum yang dilaksanakan dengan skerna hukum pidana, hukum perdata berbentuk penalti serta hukum administrasi berbentuk penghapusan ijin pengelolaan ijin usaha. Undang-undang Nomor 41 Tahun 1999 Undang-undang Nomor 19 Tahun 2004 perihal Kealasan, Undangundang Nomor 32 Tahun 2009 perihal Perlindungan dan Pengelolaan Lingkungan Hidup, kitab Undang-undang Hukum Perdata, Kitab Undang-undang Hukum Pidana serta Kitab Undang-undangg Hukum Administrasi, kenyataannya tak sanggup membuat rasa kapok untuk pelaksana aksi kriminalitas pembakaran hutan dan lahan yang melaksanakan penghangusan alas serta tanah dikarenakan tetap terdapat masalah penghangusan alas yang berlangsung.
\end{abstract}

Kata Kunci: Hutan, Lingkungan, Hukum.

\begin{abstract}
The base burning which is getting more and more massive every year in the archipelago because of the large number of land clearing by burning forests. For this reason, the burning of the widening of the plinth can cause natural destruction to disturb the fitness of the residents, to be quietly located, and to obtain a good and fit nature of life, which is the feasibility of such citizens as voiced in Article 28 h paragraph (I) of the 1945 Constitution of the Republic of Indonesia. The purpose of this study was to determine the legal arrangements for forest burning agents and to know the criminal sanctions for forest fire offenders. The method used in the preparation of this research is a normative legal study using a problem study using a legal basis that applies to laws and regulations contained in the literature. The method used for the following research is juridical normative, analytical descriptive in nature, and using the statutory regulation scheme, the executor of the scorching action of bases and land that continuously carries out scorching grounds should be carried out under criminal law, civil law in the form of penalties and administrative law takes the form of abolishing the business permit management permit. Law Number 41 Year 1999 Law Number 19 Year 2004 regarding Reason, Law Number 32 Year 2009 regarding Environmental Protection and Management, Civil Code, Criminal Code and Legal Code The administration, in fact, is unable to make a sense of the craving for the executors of the crime of burning forests and land who carry out scorching of bases and land because there is still a problem of burning the base.
\end{abstract}

Keyword: Forest, Environment, Law.

\section{PENDAHULUAN}

Hutan mencorakkan sumber daya jagat dan mendiami derajat sangat vital dalam berkehidupan berbangsa dan bernegara. Kurang lebih dua sepertiga atas serarus Sembilan puluh satu juta hektar wilayah nusantara mencorakkan wilayah alas bersama komunitas yang majemuk, berangkat dari 
alas tropika daratan rendah, alas tropika daratan tinggi, sampai alas rawa gambut, alas rawa tirta tawar, dan alas bakau (mangrove) (Yangdika Dodi, 2005 11).

Pada mulanya suatu hutan dianggap dimanfaatkan secara lestari bila tebangan tahunan atau tebangan periodik tidak mengurangi kapasitas hasil dan bila setelah penebangan dilakukan diseluruh kawasan hutan, potensi tegakan dilapangan tidak berkurang dengan sebelum dilakukan penebangan (Simon, 2006: 20). Menurut Johnson (1995:23) terdapat 3 pertanyaan yang perlu dijawab yang dijadikan dasar untuk menentukan prioritas konservasi terhadap suatu sumber daya, yaitu: Apa yang perlu dilindungi, di mana wilayah yang perlu dilindungi dan bagaimana cara melindunginya? Penyebab kebakaran hutan secara tidak langsung yaitu penguasaan lahan, alokasi penggunaan lahan, insentif/disinsentif ekonomi, degradasi hutan dan lahan, dampak dari perubahan karakteristik penduduk, dan lemahnya kapasitas kelembagaan (Applegate dan Suyanto, 2001).

Harkat penting dari asal muasal energi itu makin tinggi dikarenakan alas adalah basis kebutuhan banyak manusia. Pada Undang-undang Nomor 41 mengenai kealasan, terdapat pada pasal I angka 2 yang bersuara Alas ialah satu gabungan sistem berwujud bentangan tanah mengandung basis energi kosmos hayati yang sebagian besar berupa pohon pada persaruan habitat wilayahnya, yang satunya pada yang sekitamya tak bisa diceraikan (Supriyadi Barnbang, 2013 68-69).

Lembaga Swadaya Masyarakat Wahana Lingkungan Hidup (WALHI) sudah menilik rekaan kemudaratan dari berbagai dimensi impak pembakaran alas serta tanah dan awan gas, satu diantaranya di Provinsi Jarnbi. Kemudaratan ekonomi atas simptom kemudaratan alam belaka di Jarnbi ditaksir sudah menjangkau Rp.7.000.000.000.000. Sedangkan di Riau, kemudaratan fiyangsial atas pembakaran hutan menyentuh angka Rp. 20.000.000.000.000 yakni 2.398 hektare cagar biosfer hangus berpijar, 21.914 hektare wilayah berpijar, lirna puluh delapan ribu manusia mendapatkan kendala pernafasan, serta lagi para pekerja dan siswa sekolah kesibukan hariannya terhambat.

Walhi mengutarakan bahwasannya pencetusnya ialah reaksi land clearing merupakan pembakaran alas disebabkan perintisan wilayah bakal perladangan kelapa sawit, pengembangan perusahaan kayu tak disertai oleh pengembangan alas tumbuhan, keluasaan peluang yang dialokasikan negara terhadap investor yang akan melaksanakan alterasi wilayah menjadi perladangan monokultur spektrum luas semacam perladangan kayu dan perladangan sawit dan penguatan hukum yang larnbat bakal menindaki aksi konversi dan penghangusan yang dilakukan oleh industri (Samsul lnosentius, 2015:2)

Pemicu kehangusan alas dikarenakan aspek semesta alias ala alamiah disebabkan karena halilintar, keluarnya magma gunung Merapi, pergesekan diantara perpohoyang yang selanjutnya menyebabkan recikan bara api. Pembakaran alas yang disebabkan karena halilintar serta pergesekan antara ranting pohon langka berlangsung di nusantara terutama dengan alas hujan tropis. Kemungkiyang bias berlangsung bilamana keadaan alas membolehkan, rnisalkan pada waktu musim kemarau yang lama. Atas dasar informasi sebentuk badan penelitian, alasan manusia adalah pemicu pembakaran alas pada setiap provinsi. Berdasarkan Syaufina (2008) yang terdapat pada bukunya, Kebakaran Hutan dan Lahan di nusantara, nyaris sembilan puluh sembilan persen pembakaran alas di nusantara dikarenakan oleh perbuatan manusia. Pengadaan tanah menggunakan metode menghanguskan alas sering menjadi hal yang paling sering dilaksanakan tidak hanya individu namunjuga industri. Penghangusan alas sebagai alternatif yang amat ekonomis serta gampang untuk dilaksanakan agar bisa lahan hutan tersebut dapat diganti sebagai ladang kelapa sawit, ladang karet, serta tanah perladangan yang lain sekalian meninggikan nilai lego tanah tersebut. 
Tak bisa disembunyikan bahwa kejadian pembakaran alas sudah sebagai salah satu bahaya berat serta darurat untuk dicegah, lebih lagi pada waktu yang nyaris berlangsung pada tiap tahun. Penghangusan alas maupun tanah adalah krirninalitas yang wajib diberantas dengan cara yang komprensif pada tiap komponen. Salah satu usaha untuk membahas pelaksana penghangusan alas ialah dengan menjatuhkan sanksi pidana kurungan serta penalti seberat-beratnya, guna menimbulkan efek menyesal serta sebagai bimbingan untuk yang melaksanakan perbuatan tersebut (M Hariyanto, 2015).

Uraian penguatan Hukum administrasi karena Pembakaran Hutan oleh Badan hukum perdata di salah satu provinsi di nusantara. Agar mengetahui menganalisis upaya peyangggulangan dampak penghangusan alas bagi badan hukum perdata di kabupaten tersebut. Strategi yang dipakai berupa yuridis empiris, ala yuridis memperhitungkan hukum perUndangundangan yang merancang atas penilikan tentang penguatan Hukum Administrasi dampak dari penghangusan alas dan lahan, sedangkan ala empiris dengan menilik apakah ketetapan kontrol atas penguatan Hukum Administrasi karena penghangusan alas oleh lembaga Hukum perdata terbilang diberlakukan di kabupaten tersebut.

Dari penelitian ini terdapat beberapa acuan dari penelitian sebelumnya yani Tirza Sisila Mukau (2016) menjelaskan penelitiannya mengenai Penerapan Sanksi Pidana Terhadap Pelaku Pembakaran Hutan Atau Lahan Menurut Undang-undang Nomor 32 Tahun 2009. Sri Mustika Wardani (2011) dalam penelitiannya yang berjudul Pergeseran Kekuasaan Legislasi Dari Eksekutif ke Legislatip dalam Pembentukan Perda di Kabupaten Magelang Menurut Uu No. 32 Tahun 2004. Kebijakan Pelestarian Sumber Daya Hutan Dalam Rangka Pembangunan Berkelanjutan (Nursalam)

Berangkat dari lemahnya penguatan hukum atas penggarap penghangusan alas pada negara ini, menyebabkan masih leluasanya para pelaksana melaksanakan perbuatannya yaitu membobol alas. Atas dasar penjelasan diatas, maka tujuan dari penelitian ini yaitu Pengaturan Hukum Bagi Pelaku Pembakaran Hutan. Yang kedua untuk mengetahui Hukuman Pidana Terhadap Pelaku Tindak Pidana Pembakaran Hutan.

\section{METODE PENELITIAN}

Metode Penelitian yang dipergunakan pada penyusuyang materi ini ialah pengkajian hukum normatif mempergunakan kajian permasalahan dengan menggunakan dasar hukum yang berlaku berupa peraturan perUndang-undangan dan ditunjang oleh konsep-konsep pendapat sarjana/doktrin yang terdapat pada literatur. Pada riset ini dipergunakan pendekatan suatu konsep dan pendekatan perundang-undagan, yaitu pendekatan dengan rnengkaji berdasarkan peraturan perUndang-undangan,prinsip-prinsip hukum,maupun doktrin-doktrin hukum untuk meyangggapi tema hukum yang dijumpai untuk rnedapatkan pendapat, pemikiran serta pemahaman baru selaku aturan untuk rnenamatkan kejadian yang terjadi. Adapun beberapa kausa rnateri norma baik primer dan sekunder yang digunakan ialah misalkan Undang-undang Dasar Negara Republik Indonesia, Kitab Undang Undang Hukum Pidana (KUHP), Undang-undang omor 41 Tahun 1999 Tentang Kuhutayang, Undang-undang Nomor 32 Tahun 2004 Tentang Perlindungan Dan Lingkungan Hidup. Selain itu juga berpedoman pada artikel, literatur-literatur, jumal hukum dan yang lain terkait dengan permasalahan.

\section{HASIL DAN PEMBAHASAN}

\section{Pengaturan Hukum Bagi Pelaku Pembakaran Hutan di Indonesia}

Pembakaran-pembakaran yang selalu berjalan disamaratakan menjadi pembakaran alas, sedangkan beberapa banyak (999\%) pembakaran iru ialah penghangusan yang bemiat dilaksanakan ataupun disebabkan kealpaan, baik oleh pekebun nomaden maupun oleh pelaksana bidang usaha kerimbaan maupun perladangan, akan tetapi sekurangnya $(0,1 \%)$ yakni dikarenakan oleh kosmos (halilintar, magma gunung berapi). Saharjo rnengutarakan yakni baik pada sektor HTI, alas kosmos dan perladangan nomaden becus disuarakan bahwa $99 \%$ asal muJa penghangusan alas di nusantara yakni bermula pada kelakuan individu perorangan, mungkin telah terencana dihanguskan maupun disebabkan oleh api yang mencuat yang terlangsung impak kealpaan disaat persiapan tanah, alat pembakaran serta api adalah komponen berarti guna menyiapkan wilayah perkebuyang dan pertanian. Penghangusan selain diduga gampang serta ekonomispun memperoleh hasil komponen barang tambang yang tersedia diresap untuk tanaman. 
melimpahnya besaran komponen penghangusan yang dihanguskan pada tanah akibatnya bakal mengakibatkan kabut kuat serta kehancuran alam yang besar. Karena itu, supaya akibat alam yang disebabkannya minim, lalu pemakaian api serta komponen penghangusan saat persiapan tanah rnestilah ditata dengan cara teliti serta perlahan. Agar dapat menamatkan problematika tersebut kemudian tata laksana pencegahan ancaman pembakaran mesti berpedoman pada dapatan riset serta tak masih cuma menggantungkan pada alih bahasa buku panduan maupun pengetahuan oleh negeri lainnya walaupun belum rnencocokkan pada kondisi tanah di Indonesia.

Terdapat dua jenis sebab terjadinya pembakaran alas ialah karena kosmos serta karena tindakan individu. Pembakaran alas yang dikarenakan akibat segi kosmos dapat berbentuk kehausan, periode kemarau yang berkelarnaan, serta hantaman halilintar. Berlangsungnya aliran udara yang kuat pun dapat mengakibatkan pembakaran alas. Bilamana dua batang pohon bersinggungan dikarenakan terhempas aliran udara yang kuat kemudian dapat memicu api minim yang menjelma akbar. Pembakaran alas yang diakibatkan karena segi kelakuan individu ialah penghangusan alas dengan cara berencana guna membuat wilayah untuk perladangan, menjatuhkan batang rokok secara sembarangan, serta menghanguskan limbah pada daerah alas. Segi kelakuan individu selaku pencetus pembakaran alas lebih banyak ketimbang oleh segi kosmos. Selaku sampel 95 persen pembakaran alas di nusantara diakibatkan karena kelakuan individu.

Penyebab pembakaran alas di nusantara sebagian besar (99\%) dikarenakan individu karena direncanakan ataupun karena kealpaannya. Sebaliknya selanjutnya dikarenakan oleh kosmos (misalnya serupa magma gunung Merapi serta hantaman halilintar). Sebab pembakaran alas karena ulah individu bisa dijabarkan seperti ini

1. Konversi lahan Pembakaran yang diakibatkan karena api yang bermula pada aktivitas persiapan (penghangusan) tanah bagi perkebuyang, perusahaan, pembentukan lintasan, titian, konstruksi, serta lainnya;

2. Pembakaran Vegetasi pembakaran yang diakibatkan karena api yang bermula pada penghangusan vegetasi yang direncanakan akan tetapi tak teratasi dan lalu berlangsung api loncat, misalkan pembuatan wilayah HTI serta perladangan. Persiapan tanah yang dilakukan warga;

3. Kegiatan untuk penggunaan basis energi kosmos penghangusan yang diakibatkan karena api yang bermula pada kegiatan semasa penggunaan basis energi kosmos (Adinugroho, W I C.N .N Suryadiputra,Bambang Hero Saharjo,Labueni Siboro, 2004).

Akibat karena penghangusan aJas serta tanah ialah munculnya awan asbut. Awan asbut sudah melemahkan mutu oksigen pada wilayah yang terdampak awan asbut. Asbut pembakaran alas berakibat untuk seluruh bidang aktivitas yang terdampak efek awan asbut, maupun pada bidang kebugaran, bidang pembelajaran, bidang keuangan, bidang turisme dan berakibat dengan afiliasi antarbangsa Negeri Nusantara pada Negeri terdekatnya yang terdampak efek awan asbut. Mengamankan pembakaran alas karena perilaku seseorang atau individu, menjadi salah satu problematika yang patut menjadi atensi yang mendalam. Karena ada salah satu kelaziman yang amat jelek pada warga, spesifiknya pada sektor perladangan yang saat membentuk perladangan kerapkali mengandalkan penghangusan alas menjadi alternatif baku. pembakaran tersebut, beberapa banyak terlaksana dikarenakan kelakuan individu, apalagi pembenrukan wilayah perkebuyang melalui penghangusan. Kehancuran yang berlangsung dikarenakan pemotongan batang pohon dengan skala yang besar pun menyebabkan alas tambah beresiko dengan berlangsungnya pembakar.

Menjadi akibat pada kerap berlangsungnya pembakaran alas yang dilaksanakan dari manusia, dengan teguh wajib dihaJangi. Kitab Undang-undang Hukum Pidanapun tidak menganjurkan fondasi norma serta kontrol tentang aksi kriminalitas penghangusan alas serta tanah, maka negara melaksanakan salah satu usaha lewat membuat sejumlah peraturan yang berhubungan dengan aksi kriminalitas penghangusan alas serta tanah menjadi norma lex specialis. Peraturan itulah yang memerankan fondasi bagi orang-orang pendiri norma menjaring pelaksana aksi kriminaJitas penghangusan alas serta tanah.

Akibat spontan karena pembakaran alas itu diantaranya adalah, satu, munculnya gangguan lnfeksi Saluran Pernafasan Akut (ISPA) dikarenakan gas pembakaran alas memuat beberapa jenis asap beracun yang rawan bilamana terhisap bagi individu. Dua, menurunnya efektifitas karya dikarenakan waktu berlangsungnya pembakaran alas secara besar-besaran, semua 
tempat belajar mengajar serta perkantoran dicutikan. Tiga, terusiknya pengangkutan pada daratan, perairan ataupun langit dikarenakan kurangnya ruang pengelihatan. Empat, munculnya permasalahan antarbangsa karena gas akibat pembakaran alas itu memunculkan kemudaratan ekonomi serta non ekonomi bagi warga sekitar serta kerap mengakibatkan polusi gas antar perbatasan (transboundaryhaze pollution) pada daerah negeri-negeri sekitar , contohnya Malaysia serta Singapura.

\section{Hukuman Pidana Terhadap Pelaku Tindak Pidana Pembakaran Hutan}

Aksi kriminalitas adalah salah satu contoh aksi yang tidak baik yang terus terlihat serta menempel ditiap corak warga, maka diartikan aksi kriminalitas bakal terus berada bagaikan kesulitan serta ketewasan yang terus terulang sama situasinya pada periode yang terus beralih antara waktu dan waktu (Arif Gosita, 1983:3).

Beberapa jenis aksi kriminalitas yang berlang ung pada warga diantaranya ialah kekejaman terhadap lingkungan, lebih-lebih bahwasannya itu sangat sering berlangsung aksi kriminalitas pengerusakan lingkungan pada beberapajenis macam serta pertumbuhannya yang merujuk kepada bertambah naiknya derajat pendidikan pada kekejaman terhadap lingkungan yaitu lebih tepatnya hutan yang semakin kompleks.

Berlandaskan definisi penjelasan aksi kriminalitas tersebut, guna memilih salah satu perlakuan rnenjadi aksi kriminalitas, aksi itu wajiblah perlakuan yang ditidak benarkan serta diultimatum menggunakan hukurn untuk objek aksi kriminalitas yang melaksanakannya alias pada definisi norma kriminalitas disebutkan yaitu siapa saja yang tidak memantuhi peraturan itu. Maksud lain dari peraturan tersebut, perilaku yang termasuk aksi kriminalitas ialah aksi yang tidak diperbolehkan pada norma dan bisa diultimatum menggunakan hukuman pidana.

Hukuman kriminal kepada tersangka penghangusan alas, telah ditata pada perUndangundangan. Karena pada perUndang-undangan yang berjalan, hukuman pidana yang diberlakukan untuk pelaksana rnemiliki berbagai macam corak berdasarkan aksi krirninalitas yang dilaksanakan. Di bawah ini berbagai macam aksi kriminalitas yang berhubungan sama penghancuran serta kontaminasi alam juga ultimatum hukuman kepada aksi kriminalitas itu Melaksanakan aksi yang menyebabkan dilewatinya pokok kualitas oksigen baik, pokok kualitas tirta, pokok kualitas tirta samudera, dan parameter pokok kehancuran lingkungan hidup. Menu rut preskriptif makna pasal 98 berisi 3 ayat. Rumusan pasal 98 ayat (I) bersuara seperti selanjutnya individu-individu secara berencana melaksanakan aksi yang menyebabkan dilewatinya oksigen baik, pokok kualitas tirta, pokok kualitas tirta samudera, serta parameter pokok penghancuran lingkunganhidup, di pidana menggunakan pidana kurungan sangat cepat tri warsa serta sangat lambat dasa warsa serta penalti sangat kurang Rp. 3.000.000.000,- serta sangat tinggi Rp. 10.000.000.000,-. Elemen objektif pasal itu berbentuk individu-individu serta secara berencana. Arti individu-individu pada pasal itu berwujud individu-individu dan Lembaga norma, maupun yang berlembaga norma ataupun yang tak berlembaga nor ma. KesimpuJ annya, pelaksana fokus peraturan pasal 98 ayat (I) tak cuma mencakup dengan individu alias perseorangan tetapi jua melingkupi perusahaan. (Mahrus Ali dan Izza Elvani, 2014 13) Akan tetapi, apabila hasil yang timbul dikarenakan kealpaan pelaksana berbentuk seseorang menderita cedera parah ataupun tewas, ultimatum hukuman sanksi jua ditambah mulai sanksi kurungan sangat cepat dwi warsa serta sangat lambat heksa warsa menjelma sanksi kurungan sangat cepat tri warsa serta sangat lambat sanga warsa, serta penalti sangat kurang Rp. 2.000.000.000,- serta sangat besar Rp. 6 . 000.000.000,- menjelma penalti sangat kurang Rp. 3. 000.000.000,- serta sangat besar Rp. 9. $000.000 .000,-$.

\section{IV .SIMPULAN DAN SARAN}

\section{Simpulan}

Dari paparan penelitian dapat disimpulkan pembakaran alas yang terjadi dalam nusantara masih sering terlaksana dengan sangat luas karena masih banyak masyarakat maupun perusahaan membentuk tanah ladang melalui pembakaran alas. Dikarenakan dengan jalan secara begitu membuka lahan tidak perlu rnengeluarkan biaya yang banyak. Tapi dampak dari pembakaran hutan tersebut tidak baik bagi rnasyarakat dan negara tetangga karena menyebabkan harnpir segala kegiatan masyarakat terganggu karena kabut asap tersebut menimbulkan beberapa penyakit seperti infeksi saluran pernapasan, asma, penyakit jantung, dan iritasi pada mata. Sehingga 
pemerintah membuat peraturan peraturan hukum yang dapat menjerat pelaku pembakaran hutan baik pelaku individu/orang maupun korporasi-korporas yang membentuk tanah ladang dalam skala besar yang berakibat semakin meluasnya kebakaran hutan atau lahan dan menyebabkan banyaknya masyarakat menjadi korban.

\section{Saran}

Kebakaran hutan di Indonesia terus terjadi hampir di setiap tahunnya dan sebagai manusia kita perlu menyadarkan sodara sodara kita yang masih rnembakar hutan demi kepentingannya saja, padahal dampak dari hal tersebut dapat merugikan banyak orang dan dirinya juga. Jadi tanamkan pada diri kita agar lebih menjaga dan mencintai hutan dalam hal kecil sekalipun. Pernerintah seharusnya lebih ketat menjalan peraturan yang telah di buat supaya rnenyarnpaikan dampak insaf kepada masyarakat atau perusahaan yang lagi membakar alas secara besar besarran hingga dapat mengurangi perilaku membakar hutan secara membabi buta.

\section{DAFTAR PUSTAKA}

Adinugroho, W.C., Suryadiputra, I. N.N., Suharjo, B.H., \& S. L. (2004). Paduan Pengendalian Kebakaran Hutan dan Lahan Gambut (S. H. Bambang (ed.)). Wetlands InternationalIndonesia Programe.

Ali Mahrus, E. I. A. (2014). HUKUM PIDANA LINGKUNGAN Sistem Pidanaan Berbasis Konservasi Lingkungan Hidup. UII Press Yogyakarta. Yogyakarta.

Gosita, A. (1983). Masalah Karban Kejahatan. Akademika Pressindo.Jakarta.

Johnson, N. (1995). Biodiversity inThe Balance: Approach to Setting Geographic Conservation Priorities. Biodiversity Support Program. World Wildlife Fun. Washington DC.

Mukau, T. S. (2016). Penerapan Sanksi Pidana Terhadap Pelaku Pembakaran Hutan Atau Lahan Menurut Undang-undang Nomor 32 Tahun 2009. Lex Crimen, Vol.5.

Nandika Dodi. (2005). Hutan Bagi Ketahanan Nasional. Muhammadiyah University Press.Surakarta.

Simon, H. (2006). Hutan Jati dan Kemakmuran, Problem dan Strategi Pemecahannya. Pustaka Pelajar.Yogyakarta.

Supriyadi Eko Bambang. (2013). Hukum Agraria Kehutanan: Aspek Hukum Pertanahan dalam Pengelolaan Hutan Negara. Rajawali Pers. Jakarta.

Suyanto S, A. G. (n.d.). Akar penyebab dan dampak kebakaran hutan dan lahan di Sumatera. ICRAF.Bogor

Syaufina L. (2008). Kebakaran Hutan dan Lahan di Indonesia. Bayumedia. Malang. 